\title{
THE EFFECTS OF CURCUMA LONGA L. LEAF EXTRACTS ON THE PREVENTION OF OXIDATION IN SOYBEAN OIL
}

\author{
Izabel de Paula Duarte Alves, Maria Carolina de Almeida ${ }^{凶}$, \\ Luciana Reis Fontinelle Souto, Tatianne Ferreira de Oliveira \\ Food Technology Department, School of Agronomy, Federal University of Goiás - UFG \\ Campus Samambaia, Rodovia GO 462, Km 0, Caixa Postal 131, CEP 74690-900, Goiânia-Goiás, Brazil
}

\begin{abstract}
Background. The use of natural plant antioxidants has been an alternative approach to synthetic antioxidants for food applications. This study investigated the antioxidant properties of the leaves of Curcuma longa L. against the oxidation of soybean oil using leaf extracts obtained from seven different types of organic solvents and compared to the action of efficient synthetic antioxidants which are widely used and low cost but with toxicity risk. The application of natural alternatives from sources still little studied is a proposal and the extraction of compounds with high antioxidant capacity may vary according to the type of solvent, its mixture, its polarity and other factors that burden or harm the health of the consumer.

Materials and methods. The leaf extracts were sanitized, dried, and obtained for solvent selection. The quantification of total phenolic compounds (TPC) and antioxidants was performed by using different combinations and proportions of solvents: water $(100 \%)$, ethanol $(100 \%)$, methanol $(100 \%)$, ethanol/water (70\%:30\%), methanol/water (70\%:30\%), methanol/acetic acid (99.5\%:0.5\%), and acetone/water/acetic acid (70\%:28:2\%). The solvent selected was the one that extracted the highest content of phenolic and antioxidant compounds (using the free radical DPPH scavenging method and FRAP assay). It used an accelerated storage test and experimental design to assess oxidative stability (using peroxide index (PI), thiobarbituric acid reactive substances (TBARS), dienes (DC) and triple conjugates (TC) and statistical analysis).

Results. The ethanol/water solvent was efficient in the extraction of TPC (2422 mg GAE $\left.100 \mathrm{~g}^{-1}\right)$. The mixture of solvents extracted an average of $23.65 \%$ more TPC when compared to the single solvents. Regarding

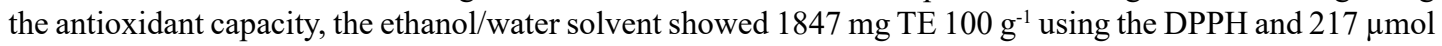
of $\mathrm{FeSO}_{4} 100 \mathrm{~g}^{-1}$ using the FRAP assays. In addition, the oxidation of soybean oil was delayed by the accelerated storage test showing equivalent results to BHT at $0.02 \%$ for the values of PI, TBARS and DC/TC. Conclusion. The E/W extract showed the highest yield in the extraction of phenolic compounds and is a safe solvent for food. The addition of Curcuma longa L. leaf extract to soybean oil caused reductions in PI, TBARS, CD and CT values. The leaf extract of $C$. longa $\mathrm{L}$. is considered to be a good alternative to synthetic antioxidants against the oxidative degradation of soybean oil.
\end{abstract}

Keywords: natural antioxidants, extraction, total phenolic content, oxidative stability

\section{INTRODUCTION}

Oxidative processes are the main cause of the degradanutritional properties of food in addition to the possition of oils and fats, which can change the sensorial and 
The addition of antioxidant compounds is performed in the food industry to prevent or delay oxidative reactions (Carocho et al., 2018). Synthetic antioxidants such as butylated hydroxyanisole (BHA), butylated hydroxytoluene (BHT), tert-butylhydroquinone (TBHQ) and propyl gallate (PG) are the most commonly used ones because of their low cost and high efficiency (Taghvaei et al., 2015). However, the use of these compounds is strongly regulated in several countries due to the potential side effects and toxicity demonstrated in recent studies (Wang et al., 2018). Therefore, the use of natural antioxidants from plants has been an alternative approach to synthetic antioxidants and is widely studied to be applied in food (Alizadeh et al., 2019). The process of obtaining a plant extract to be applied as a natural antioxidant requires a consideration of the choice of a non-toxic solvent type and concentration and the adequate polarity of the solvent to extract the target compounds (Pedro et al., 2018). Among the potential sources of natural antioxidants, $C$. long $\mathrm{L}$. (saffron) is a plant of Asian origin mainly grown for its rhizomes. It provides a spice widely used since ancient times in cooking and medicine. Several studies have demonstrated the wide range of pharmacological activities of its compounds (Wojcik et al., 2018). C. lon$g a \mathrm{~L}$. leaves are not widely used and are considered to be a residual product during post-harvest operations. The data on their composition and antioxidant potential are scarce. However, some studies have reported a high content of phenolic compounds in these leaves (Braga et al., 2018) which provide antioxidant properties that can be used in the food industry to prevent the oxidative degradation of oils. In this context, the objective of this work was to extract the phenolic compounds from $C$. longa $\mathrm{L}$. leaves using seven different solvents and to use the extract with the highest yield to evaluate the oxidative stability of soybean oil in comparison with a synthetic antioxidant.

\section{MATERIALS AND METHODS}

\section{Sample preparation}

The leaves of $C$. longa L. were collected between December 2018 and April 2019 at the Cooperative of Saffron Producers (Cooperaçafrão) (Mara Rosa, Goiás,

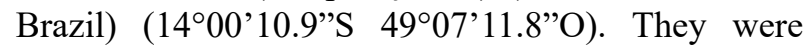
stored in nylon bags and kept under refrigeration in the laboratory in the Department of Food Engineering at the School of Agronomy of the Federal University of Goiás (Goiânia, Goiás, Brazil) for $24 \mathrm{~h}$.

The leaves were selected according to their typical green color and integrity. They were washed with drinking water and sanitized using sodium hypochlorite solution $\left(0.1 \mathrm{~mL} \mathrm{~L}^{-1}\right)$ for $15 \mathrm{~min}$. The stems were removed and the leaves were cut into approximately $2 \mathrm{~cm}$ squares, placed in perforated stainless steel trays and subjected to convective drying at $40^{\circ} \mathrm{C}$ (Braga et al., 2018) in an air circulation oven (Tecnal. TE-394/3, Piracicaba, Brazil) for $72 \mathrm{~h}$ (final humidity was 10.29

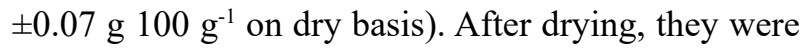
packed in vacuum plastic bags and stored in cool airy conditions protected from light at room temperature until analysis.

\section{Obtaining extracts and selecting solvents}

The quantification of TPC and antioxidants were performed by using 7 different combinations and proportions of solvents, which are water (W, 100\%), ethanol (E, 100\%), methanol (M, 100\%), ethanol/water (EW, 70\%:30\%), methanol/water (MW, 70\%:30\%), methanol/acetic acid (MAC, 99.5\%:0.5\%), and acetone/ water/acetic acid (AWA, 70\%:28\%:2\%), as proposed by Michiels et al. (2012). This previous study was necessary to be sure that the solvent used would have a good extraction as there are not many studies in the literature with the Curcuma longa $\mathrm{L}$. It was mixed to $1 \mathrm{~g}$ of a dehydrated sample at $20 \mathrm{~mL}$ of each extractive solution followed by stirring in a magnetic mixer (Tecnal. TE-089, Piracicaba, Brazil) at room temperature $\left(25^{\circ} \mathrm{C} \pm 2^{\circ} \mathrm{C}\right)$ for $1 \mathrm{~h}$. The extracts were then filtered and the solid residue was scraped from the filter and extracted again with $20 \mathrm{~mL}$ of the solvent under the same conditions as performed before. The volume of each extract was measured to $50 \mathrm{~mL}$ before being stored in amber flasks at $-20^{\circ} \mathrm{C}$. The solvent selected was the one that extracted the highest TPC and antioxidant compounds (using free radical DPPH scavenging methods and FRAP).

\section{Analyses of total phenolic content and antioxidant capacity}

The TPC was determined for each of the extracts prepared according to item 2.2 following the spectrophotometric method proposed by Chan et al. (2007). The 
result of the TPC was expressed as mg of gallic acid equivalent (GAE) per $100 \mathrm{~g}$ of sample dry matter. The antioxidant capacity was measured by analysing the DPPH and FRAP. The analysis of DPPH was performed according to Chan et al. (2007) with modifications $(1 \mathrm{~g}$ of dry leaf to $20 \mathrm{~mL}$ of the selected solvent). The radical scavenging activity was calculated as IC50 and expressed as a Trolox equivalent antioxidant capacity (TE) in mg of Trolox per 100 grams of material as follows:

$$
\mathrm{TE}, \mathrm{mg} \mathrm{TE} \cdot 100^{-1} \cdot \mathrm{g}^{-1}=\frac{\mathrm{IC}_{50}(\text { Trolox })}{\mathrm{IC}_{50}(\text { sample })} \cdot 10^{5}
$$

where:

IC - amount of substance required for $50 \%$ reduction in the concentration of DPPH ion.

The iron reducing power (FRAP) was evaluated using the method suggested by Pulido et al. (2000) with modifications (tripled quantities, maintaining proportions). The result was expressed in $\mu \mathrm{Mol} \mathrm{FeSO}_{4}$ per 100 grams of material.

\section{Accelerated storage test and experimental design}

The accelerated storage test was carried out using the extract with the highest yield obtained previously and according to the methodology proposed by Mohd Nor et al. (2009) where the temperatures chosen were close to those used in accelerated storage tests in the literature. The parameters of the concentration of the extract of C. longa $\mathrm{L}$. leaves (\%) and temperature $\left({ }^{\circ} \mathrm{C}\right)$ were studied according to Table 1. A complete factorial design $2^{2}$ was used with 3 repetitions at the central point in a total of 7 assays.

Refined, bleached and degummed soybean oil was used without the addition of synthetic antioxidants. The ethanolic extract of leaves of C. longa $\mathrm{L}$. were first added to $100 \mathrm{~g}$ of oil in $150 \mathrm{~mL}$ transparent glass beakers. The beakers remained under heat in an oven (Quimis, Q-317B232, Brazil) for 12 days. Aliquots were removed every 3 days to evaluate the oxidative

Table 1. Values used in complete factorial design for two factors

\begin{tabular}{lcccc}
\hline \multicolumn{1}{c}{ Variables } & Code & -1 & 0 & +1 \\
\hline Extract concentration, \% & $x_{1}$ & 0.5 & 1.0 & 1.5 \\
Temperature, ${ }^{\circ} \mathrm{C}$ & $x_{2}$ & 50 & 60 & 70 \\
\hline
\end{tabular}

stability parameters. A blank and a positive control (oil without synthetic antioxidant BHT or ethanolic extract

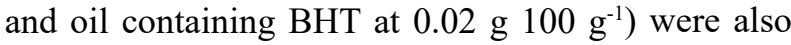
evaluated for each temperature studied $\left(50,60,70^{\circ} \mathrm{C}\right)$ under the same experimental conditions.

\section{Evaluation of oxidative stability}

Peroxide index (PI). The PI test was carried out according to AOCS (2003). This method is based on the mixture of $1 \mathrm{~g}$ of soybean oil with $50 \mathrm{~mL}$ of $3: 2(\mathrm{v} / \mathrm{v})$ acetic acid/iso-octane solution and $0.5 \mathrm{~mL}$ of a freshly saturated potassium iodide (KI) solution. The sample was titrated with $0.01 \mathrm{~mol} / \mathrm{L}$ sodium thiosulfate solution $\left(\mathrm{Na}_{2} \mathrm{~S}_{2} \mathrm{O}_{3}\right)$ until the blue color completely disappeared due to the use of $0.5 \mathrm{~mL}$ of $1 \%$ starch solution as an indicator. The test was performed in duplicate along with a control test. The calculation was performed according to equation 2 :

Peroxide index, $\mathrm{mEq} \frac{\text { peroxide }}{\mathrm{kg}}=\frac{(S-B) \cdot N \cdot 1000}{P_{A}}$ where:

$S-\mathrm{mL}$ of $0.01 \mathrm{~mol} / \mathrm{L}$ sodium thiosulfate solution was used as the titrant in the titration of the samples,

$B-\mathrm{mL}$ of the $0.01 \mathrm{~mol} / \mathrm{L}$ sodium thiosulfate solution was used as the titrant in the titration of the control,

$N$ - concentration of the sodium thiosulfate solution, $\mathrm{mol} / \mathrm{L}$,

$P_{A}$ - weight of the sample, g.

The result was expressed in milliequivalent $(\mathrm{mEq})$ peroxide per $\mathrm{kg}$ of the sample analyzed.

Thiobarbituric acid reactive substances (TBARS). The TBARS assay was performed according to Tarladgis et al. (1960), in which $10 \mathrm{~g}$ of the sample was previously mixed with $50 \mathrm{~mL}$ of distilled water. The mixture was distilled in a Kjeldahl distillation flask, collecting $50 \mathrm{~mL}$ of the distillate at the end. In a test tube, $5 \mathrm{~mL}$ of the distillate, $5 \mathrm{~mL}$ of the TBA solution $(0.5766 \mathrm{~g}$ of thiobarbituric acid diluted in $20 \mathrm{~mL}$ of distilled water and $180 \mathrm{~mL}$ of acetic acid P.A.) were added and stirred. The absorbance of the sample was measured using a spectrophotometer (Rayleigh model UV 800, Beijing, China) at $538 \mathrm{~nm}$. The calculation was done by multiplying the absorbance reading by 7.8 (experimental 
value) and was expressed in $\mathrm{mg}$ of malonaldehyde (MDA) per $1000 \mathrm{~g}$ of the sample analyzed.

Dienes (CD) and triple conjugates (CT). The CD and CT were analyzed according to the AOCS method (1990). A volume of $10 \mathrm{~mL}$ of isooctane P.A. was added to the sample $(0.01 \mathrm{~g})$. The absorbance was measured at $233 \mathrm{~nm}$ (dienes) and $270 \mathrm{~nm}$ (trienes) using a quartz cuvette. The dilutions were performed to obtain absorbance values between $0.1-0.8$. The calculation was done according to equation 3 :

$$
\frac{A \Lambda}{c l}=K \Lambda
$$

where:

$K \Lambda-E^{1 \%}{ }_{1 \mathrm{~cm}}-$ specific extinction at wavelength,

$A K$ - absorbance measured at wavelength,

$c$ - concentration of the solution, $\mathrm{g} 100 \mathrm{~mL}^{-1}$,

$l \quad$ - light path of the cuvette, $\mathrm{cm}$.

\section{Statistical analysis}

The data were analyzed by ANOVA Tukey test $(p<$ 0.05). The STATISTICA 7.0 program (StatSoft Inc., Tulsa, Oklahoma, USA) was used with a significance level of $95 \%(p<0.05)$.

\section{RESULTS AND DISCUSSION}

\section{Total phenolic content and antioxidant capacity}

The TPC and antioxidant capacity in the leaf extracts of $C$. longa $\mathrm{L}$. are in Table 2.
It can be observed that the composition of the extracting solvents significantly affected $(p<0.05)$ the TPC and antioxidant capacity measured. Among the use of single solvents, methanol $\mathrm{M}$ promoted the highest extraction of TPC, showing an $87 \%$ higher extraction than the water extract $\mathrm{W}$, which was responsible for the lower extraction. The AWA, MW and EW presented a more efficient extraction among the mixture of solvents used. They presented $16.62 \%$ more TPC extracted than those that showed the lowest amount. The solvent mixture extracted an average of $23.65 \%$ more TPC than the individual solvents.

Michiels et al. (2012) reported that the extraction properties of the solvents significantly affected the measured TPC ( $\pm 25 \%$ variation $)$ and the antioxidant capacity (up to $30 \%$ variation), and also that the most efficient solvent for the extraction of phenolic compounds depends on the food matrices analyzed. The DPPH and FRAP assays showed a statistically significant difference when the solvent used $(p<0.05)$ was changed. In the DPPH assay, the extracts using just $\mathrm{E}$ and the mixture of MW presented the highest antioxidant capacity with an average of $90 \%$ higher when compared to the extracts of $\mathrm{M}$ which presented the lowest value. The extracts using other solvents showed no significant difference between them.

In the FRAP assay, the extracts using the solvents MW, EW and AWA presented the highest antioxidant capabilities with no statistical difference between them. The results of the FRAP assay showed that the extracts using a mixture of solvents presented

Table 2. Total phenolic content and antioxidant activity in the leaf extracts of C. longa L. obtained using seven different solvents

\begin{tabular}{lccc}
\hline Solvent & TPC & $\begin{array}{c}\text { DPPH } \\
\text { mg TE } 100 \mathrm{~g}^{-1}\end{array}$ & $\begin{array}{c}\text { FRAP } \\
\text { Mol FeSO }_{4} 100 \mathrm{~g}^{-1}\end{array}$ \\
\hline $\mathrm{W}$ & $273 \pm 39.69^{\mathrm{e}}$ & $3337 \pm 341.41^{\mathrm{b}}$ & $65 \pm 20.64^{\mathrm{d}}$ \\
$\mathrm{E}$ & $1042 \pm 65.05^{\mathrm{d}}$ & $8587 \pm 341.41^{\mathrm{a}}$ & $119 \pm 5.61^{\mathrm{d}}$ \\
$\mathrm{M}$ & $2148 \pm 166.42^{\mathrm{c}}$ & $777 \pm 0^{\mathrm{b}}$ & $200 \pm 13.81^{\mathrm{bc}}$ \\
$\mathrm{E} / \mathrm{W}$ & $2422 \pm 141.16^{\mathrm{bc}}$ & $1847 \pm 1306.08^{\mathrm{b}}$ & $217 \pm 6.43^{\mathrm{abc}}$ \\
$\mathrm{M} / \mathrm{W}$ & $2723 \pm 81.62^{\mathrm{ab}}$ & $7274 \pm 1204.77^{\mathrm{a}}$ & $263 \pm 12.32^{\mathrm{a}}$ \\
$\mathrm{M} / \mathrm{A}$ & $2346 \pm 206.58^{\mathrm{bc}}$ & $1433 \pm 584.30^{\mathrm{b}}$ & $192 \pm 18.72^{\mathrm{c}}$ \\
$\mathrm{A} / \mathrm{W} / \mathrm{A}$ & $2813 \pm 142.65^{\mathrm{a}}$ & $150 \pm 0^{\mathrm{b}}$ & $255 \pm 17.69^{\mathrm{ab}}$ \\
\hline
\end{tabular}


an average of $75 \%$ higher antioxidant capacity when compared to the extract using just $\mathrm{W}$. The solvents that presented the best results from the FRAP assay also showed the best extraction of phenolic compounds from the DPPH assay.

The data demonstrated that the combination of solvents with $\mathrm{W}$ obtained better results than the use of single solvents. The higher efficiency of mixtures of organic solvents and $\mathrm{W}$ when compared to the use of a monosolvent system can be explained by the high solubility of the glycosylated phenolic compounds in W. The use of $\mathrm{M} / \mathrm{W}$ and $\mathrm{E} / \mathrm{W}$ also extracts the non-glycosylated compounds well because of the high availability of free electrons from the solvents M and E (Pedro et al., 2018). The type of solvent and polarity play a fundamental role in increasing phenolic solubility by affecting the single electron transfer and the hydrogen atom transfer, which are key aspects in measuring the antioxidant capacity (Pérez-Jiménez et al., 2006). The differences in the structure of phenolic compounds also influence their solubility in solvents of different polarities. Therefore, the type of extraction solvent, as well as the insulation, can have an impact on the yield of polyphenols extracted from plant material (Złotek et al., 2016).

A greater amount of TPC (834\%) (2148.31 mg of GAE $100 \mathrm{~g}^{-1}$ ) was determined in the extract $\mathrm{M}$ of the leaves of $C$. long $a \mathrm{~L}$. when compared to that found by Chan et al. (2007) for the same species grown in Malaysia. In the other vegetables, the CTP found in the leaves of $C$. longa $\mathrm{L}$. was superior to that found in the extracts (M) and (E) of the broccoli variety Italica and leek cultivar Blue Liege (AWA extract, $120 \mathrm{mg}$ of GAE $100 \mathrm{~g}^{-1}$ and $80 \mathrm{mg}$ of GAE $100 \mathrm{~g}^{-1}$, respectively; Michiels et al., 2012). However, they showed less extraction of TPC when compared to the lyophilized leaf of basil Ocimum basilicum L. (AWA extract, 15000 mg of GAE $100 \mathrm{~g}^{-1}$; Złotek et al., 2016).

Priya et al. (2012) obtained an IC50 of $3.227 \mathrm{mg}$ $\mathrm{mL}^{-1}$ for DPPH radicals at an extract concentration of $4 \mathrm{mg} \mathrm{mL}^{-1}$ and an IC50 below $100 \mathrm{mg}$ GAE $100 \mathrm{~g}^{-1}$ for FRAP in the extract concentration of $800 \mathrm{mg} \mathrm{mL}^{-1}$ with oil from $C$. longa $\mathrm{L}$. leaves. It is considered that the effect of antioxidants on DPPH is due to its ability to donate hydrogen. The authors concluded that the oil of $C$. longa $\mathrm{L}$. leaves can act as a proton donor and antioxidant. The extracts containing acetone and $\mathrm{M}$ have high amounts of TPC and antioxidant capacity.
Regarding the toxicity of the solvents, E and $\mathrm{W}$ are considered safer solvents than acetone, $\mathrm{M}$ and other organic solvents, and therefore they are recommended for use in food (Balboa et al., 2014). Thus, the EW extract was considered the most suitable one to be applied in soybean oil.

\section{Evaluation of oxidative stability}

Peroxide index (PI) and thiobarbituric acid reactive substances (TBARS). The results of PI and TBARS index are shown in Table 3, Figure 1 and Figure 2.

PI is an indicator of the oxidation state in the early stages of lipid oxidation and also a measure of the content of hydroperoxides and primary compounds in oil samples (Zamuz et al., 2018). From the oil samples with extracts of leaves of $C$. longa $\mathrm{L}$., it can be observed that the oil with extract of $1.0 \%$ showed a similar response to BHT until the 6th day of testing. This extract concentration also showed a greater reduction in PI since this parameter increased from day 3 . The PI in oil containing $1.5 \%$ of extract was lower than that with BHT at $70^{\circ} \mathrm{C}$. However, the use of $0.5 \%$ showed a similar response to this positive control and both with lower than white.

These results showed that the temperature positively influenced the formation of peroxides. This can be noted from the increase in PI from $50^{\circ} \mathrm{C}$ to $70^{\circ} \mathrm{C}$ in the concentration of $0.5 \%$. Considering that the lower the PI the lower the oxidation rate of the sample and the greater its oxidative stability, the leaf extracts of C. longa L. contributed to the oxidative stability of soybean oil. These data can be compared to those obtained by Mohd Nor et al. (2009), who performed an accelerated storage test using palm oil heated to $60^{\circ} \mathrm{C}$ and found that the peroxide values were significantly reduced by the E extract of $C$. long $a$ L. leaves in a dose dependent manner. These authors determined that this extract has good antioxidant capacity and is another potential source of natural antioxidants to be explored in the food industry.

The PI of microencapsulated fish oil in the presence of $0.15 \%$ rosemary extract were lower $(3.08 \mathrm{mEq}$ peroxide $\mathrm{kg}^{-1}$ of oil) than the control group using commercial antioxidant BHT (4.25 mEq peroxide $\mathrm{kg}^{-1}$ oil $)$ at the tested temperatures (Yeşilsu et al., 2019). Our study also showed lower PI values at a concentration of $1.0 \%$ of the leaf extract of C. longa L. $(10.8 \mathrm{mEq}$ 
Alves, I. de Paula Duarte, Almeida de, M. C., Souto Reis Fontinelle, L., Ferreira de Oliveira, T. (2021). The effects of Curcuma longa L. leaf extracts on the prevention of oxidation in soybean oil. Acta Sci. Pol. Technol. Aliment., 20(3), 325-336. http://dx.doi.org/10.17306/ J.AFS.2021.0894

Table 3. Peroxide index (PI) and thiobarbituric acid reactive substances (TBARS) in soybean oil subjected to accelerated storage test for 12 days

\begin{tabular}{|c|c|c|c|c|c|c|c|}
\hline \multirow{2}{*}{ Tests } & \multirow{2}{*}{$\begin{array}{c}x_{1} \\
\text { C, \% }\end{array}$} & \multirow{2}{*}{$\begin{array}{c}x_{2} \\
\mathrm{~T},{ }^{\circ} \mathrm{C}\end{array}$} & \multicolumn{5}{|c|}{ Time, days } \\
\hline & & & 0 & 3 & 6 & 9 & 12 \\
\hline \multicolumn{8}{|c|}{ Peroxide index (PI), mEq peroxide $\mathrm{kg}^{-1}$} \\
\hline \multirow[t]{3}{*}{ Blank } & - & 50 & $2.73 \pm 0.33$ & $4.49 \pm 0.71$ & $7.46 \pm 3.52$ & $5.42 \pm 0.62$ & $8.43 \pm 0.66$ \\
\hline & - & 60 & $2.73 \pm 0.33$ & $2.95 \pm 0.01$ & $42.08 \pm 2.55$ & $96.51 \pm 0.82$ & $163.60 \pm 6.52$ \\
\hline & - & 70 & $2.73 \pm 0.33$ & $23.36 \pm 0.66$ & $55.70 \pm 0.08$ & $120.94 \pm 0.39$ & $166.04 \pm 1.81$ \\
\hline \multirow[t]{3}{*}{ Control (BHT) } & - & 50 & $4.48 \pm 0.69$ & $5.73 \pm 2.46$ & $6.97 \pm 0.72$ & $7.15 \pm 1.12$ & $7.99 \pm 1.43$ \\
\hline & - & 60 & $4.48 \pm 0.69$ & $1.24 \pm 0.36$ & $15.62 \pm 0.33$ & $66.86 \pm 3.22$ & $102.33 \pm 1.17$ \\
\hline & - & 70 & $4.48 \pm 0.69$ & $23.11 \pm 0.36$ & $52.24 \pm 0.23$ & $84.73 \pm 2.41$ & $114.05 \pm 1.18$ \\
\hline $\mathrm{C} 1$ & 0.5 & 50 & $4.98 \pm 0.02$ & $9.45 \pm 2.14$ & $11.90 \pm 3.5$ & $9.69 \pm 0.33$ & $8.97 \pm 0.04$ \\
\hline $\mathrm{C} 2$ & 0.5 & 70 & $4.98 \pm 0.02$ & $19.96 \pm 0.67$ & $48.94 \pm 0.96$ & $82.34 \pm 2.93$ & $109.88 \pm 0.52$ \\
\hline $\mathrm{C} 3$ & 1.5 & 50 & $5.48 \pm 0.69$ & $11.67 \pm 2.48$ & $14.19 \pm 0.3$ & $14.02 \pm 0.48$ & $8.40 \pm 0.77$ \\
\hline $\mathrm{C} 4$ & 1.5 & 70 & $5.48 \pm 0.69$ & $8.45 \pm 3.53$ & $41.90 \pm 3.53$ & $71.67 \pm 0.59$ & $92.05 \pm 4.43$ \\
\hline $\mathrm{C} 5$ & 1.0 & 60 & $6.69 \pm 0.32$ & $4.47 \pm 0.04$ & $8.88 \pm 0.08$ & $32.97 \pm 1.72$ & $121.20 \pm 0.20$ \\
\hline C6 & 1.0 & 60 & $6.69 \pm 0.32$ & $6.18 \pm 0.33$ & $16.33 \pm 0.73$ & $27.11 \pm 3 . .13$ & $74.56 \pm 3.23$ \\
\hline $\mathrm{C} 7$ & 1.0 & 60 & $6.69 \pm 0.32$ & $4.67 \pm 0.31$ & $7.19 \pm 0.31$ & $47.67 \pm 0.16$ & $62.01 \pm 6.43$ \\
\hline \multicolumn{8}{|c|}{ Thiobarbituric acid reactive substances (TBARS), mg of malonaldeide $\mathrm{kg}^{-1}$} \\
\hline \multirow[t]{3}{*}{ Blank } & - & 50 & $0.20 \pm 0.02$ & $0.10 \pm 0.01$ & $0.76 \pm 0.2$ & $0.16 \pm 0.05$ & $0.19 \pm 0.03$ \\
\hline & - & 60 & $0.20 \pm 0.02$ & $0.43 \pm 0.03$ & $1.08 \pm 0.07$ & $1.05 \pm 0.01$ & $0.19 \pm 0.00$ \\
\hline & - & 70 & $0.20 \pm 0.02$ & $0.26 \pm 0.02$ & $0.71 \pm 0.04$ & $1.12 \pm 0.04$ & $1.60 \pm 0.01$ \\
\hline \multirow[t]{3}{*}{ Control (BHT) } & - & 50 & $0.13 \pm 0.05$ & $0.07 \pm 0.02$ & $0.16 \pm 0.02$ & $0.04 \pm 0.02$ & $0.24 \pm 0.04$ \\
\hline & - & 60 & $0.13 \pm 0.05$ & $0.47 \pm 0.01$ & $0.46 \pm 0.02$ & $0.63 \pm 0.02$ & $0.94 \pm 0.01$ \\
\hline & - & 70 & $0.13 \pm 0.05$ & $0.29 \pm 0.01$ & $0.88 \pm 0.01$ & $0.98 \pm 0.04$ & $1.27 \pm 0.02$ \\
\hline $\mathrm{C} 1$ & 0.5 & 50 & $0.10 \pm 0.01$ & $0.13 \pm 0.03$ & $0.19 \pm 0.03$ & $0.21 \pm 0.02$ & $0.16 \pm 0.01$ \\
\hline $\mathrm{C} 2$ & 0.5 & 70 & $0.10 \pm 0.01$ & $0.27 \pm 0.02$ & $0.94 \pm 0.02$ & $0.70 \pm 0.03$ & $1.15 \pm 0.01$ \\
\hline $\mathrm{C} 3$ & 1.5 & 50 & $0.06 \pm 0.01$ & $0.22 \pm 0.01$ & $0.18 \pm 0.01$ & $0.03 \pm 0.01$ & $0.16 \pm 0.01$ \\
\hline $\mathrm{C} 4$ & 1.5 & 70 & $0.06 \pm 0.01$ & $0.35 \pm 0.03$ & $0.59 \pm 0.02$ & $0.49 \pm 0.02$ & $1.11 \pm 0.03$ \\
\hline $\mathrm{C} 5$ & 1.0 & 60 & $0.14 \pm 0.03$ & $0.18 \pm 0.05$ & $0.71 \pm 0.07$ & $0.73 \pm 0.01$ & $1.46 \pm 0.11$ \\
\hline C6 & 1.0 & 60 & $0.14 \pm 0.03$ & $0.18 \pm 0.01$ & $0.45 \pm 0.00$ & $0.60 \pm 0.01$ & $0.83 \pm 0.09$ \\
\hline C7 & 1.0 & 60 & $0.14 \pm 0.03$ & $0.23 \pm 0.02$ & $0.48 \pm 0.01$ & $0.52 \pm 0.01$ & $0.74 \pm 0.01$ \\
\hline
\end{tabular}

Values constitute mean \pm standard deviation of two repetitions.

$\mathrm{C}$ - concentration, $\mathrm{T}$ - temperature. 

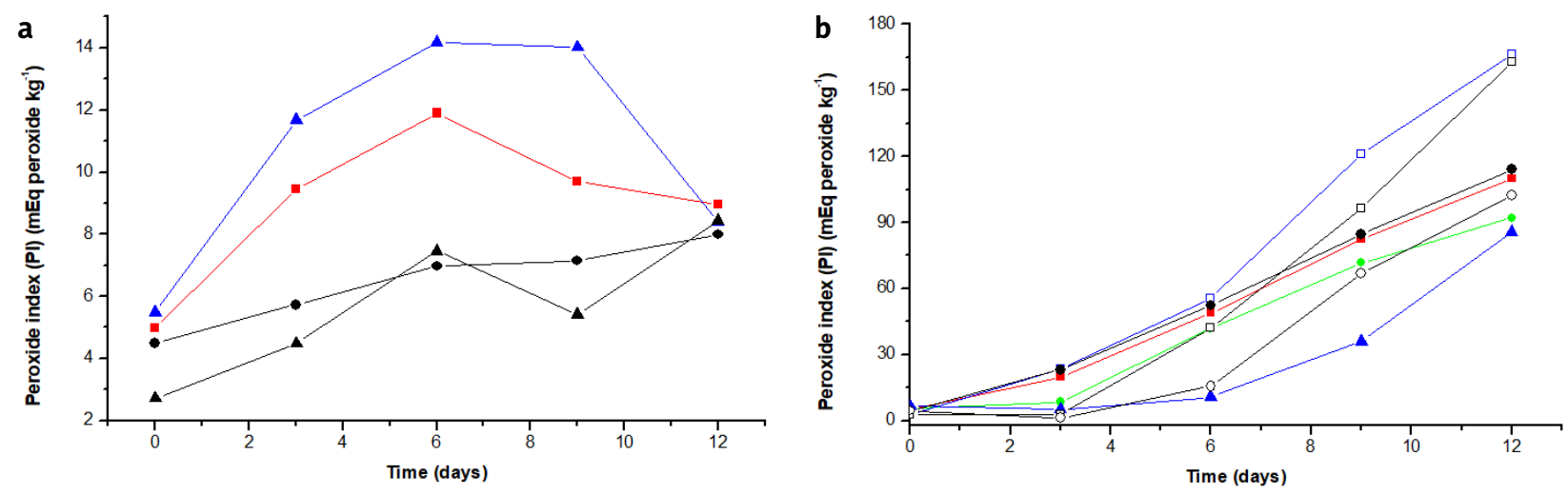

Fig. 1. Evaluation kinetics of peroxide index (PI) depending on temperature and time, $\mathrm{mEq}$ peroxide $\mathrm{kg}^{-1}$. a. Experiments at $50^{\circ} \mathrm{C}:-\mathrm{C} 1,0.5 \% ; \Delta-\mathrm{C} 3,1.5 \% ; \boldsymbol{\Delta}-$ blank, $\bullet-\operatorname{control}(\mathrm{BHT})$. b. Experiments at $60^{\circ} \mathrm{C}$ and $70^{\circ} \mathrm{C}:-\mathrm{C} 2,0.5 \%$ at $70^{\circ} \mathrm{C} ; \bullet-\mathrm{C} 4,1.5 \%$ at $70^{\circ} \mathrm{C} ; \triangle-\mathrm{C} 5,1.0 \%$ at $60^{\circ} \mathrm{C} ; \square-$ blank $70^{\circ} \mathrm{C}, \square-$ blank $60^{\circ} \mathrm{C} ; \bullet-\operatorname{control}(\mathrm{BHT})$ at $70^{\circ} \mathrm{C}, \circ-$ control (BHT) at $60^{\circ} \mathrm{C}$
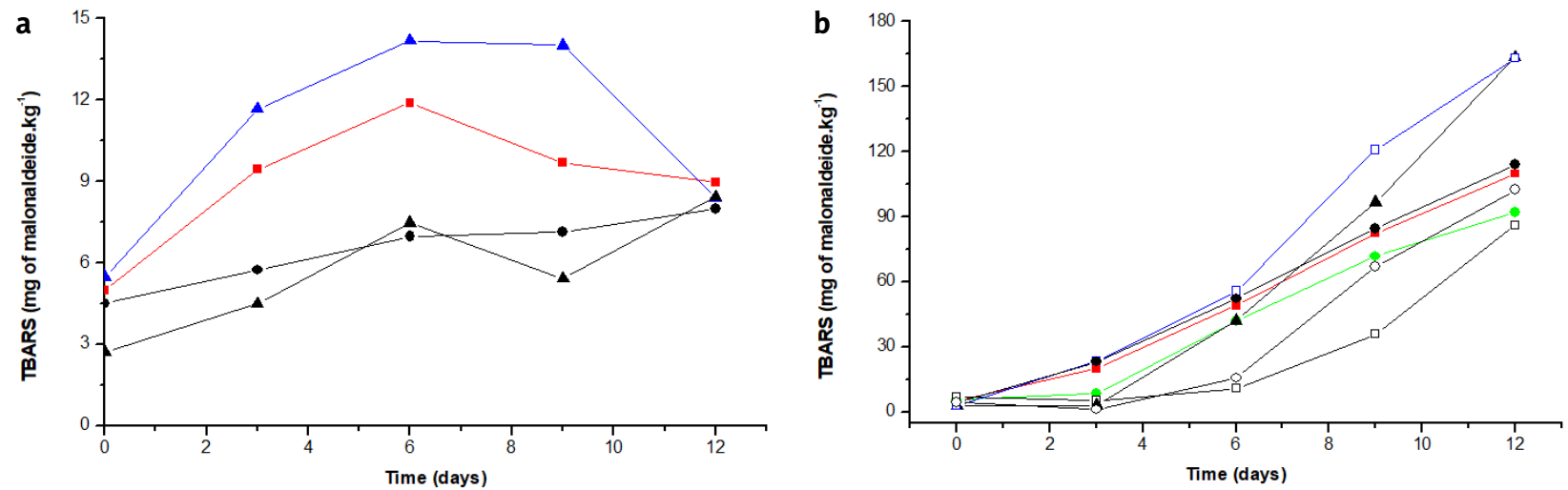

Fig. 2. Evaluation kinetics of thiobarbituric acid reactive substances (TBARS) depending on temperature and time. a. Experiments at $50^{\circ} \mathrm{C}:-\mathrm{C} 1,0.5 \% ; \Delta-\mathrm{C} 3,1.5 \% ; \boldsymbol{\Delta}-$ blank, $\bullet-$ control $(\mathrm{BHT})$. b. Experiments at 60 and $70^{\circ} \mathrm{C}:-\mathrm{C} 2$, $0.5 \%$ at $70^{\circ} \mathrm{C} ; \bullet-\mathrm{C} 41.5 \%$ at $70^{\circ} \mathrm{C} ; \boldsymbol{\Delta}-\mathrm{C} 5,1.0 \%$ at $60^{\circ} \mathrm{C} ; \square-$ blank $70^{\circ} \mathrm{C}, \square-$ blank $60^{\circ} \mathrm{C} ; \bullet-\operatorname{control}(\mathrm{BHT})$ at $70^{\circ} \mathrm{C}$, $\circ-$ control (BHT) $60^{\circ} \mathrm{C}$

peroxide $\mathrm{kg}^{-1}$ of oil) when compared to the control using BHT (15.62 $\mathrm{mEq}$ peroxide $\mathrm{kg}^{-1}$ of oil) at a temperature of $60^{\circ} \mathrm{C}$ on the $6^{\text {th }}$ test day with greater inhibition in the formation of peroxides that mainly occurred on the $6^{\text {th }}$ and $9^{\text {th }}$ days. According to international standardization, the maximum level of peroxides in oils is up to 10 milliequivalents of active oxygen $\mathrm{kg}^{-1}$ of oil. It was observed that the oil containing leaf extract of
C. longa $\mathrm{L}$. showed a PI average of 10.8 milliequivalents of active oxygen $\mathrm{kg}^{-1}$ of oil on day 6 , whereas the PI in the oil containing BHT was $15.62 \mathrm{mEq}$ of active oxygen $\mathrm{kg}^{-1}$ of oil during the same period and with the same temperature tested. Thus, the PI values of extracts of $C$. longa L. were within the maximum acceptable concentration. The BHT, however, presented greater PI values than the maximum allowed (FAO, 1999). 
The 1.1.3.3-tetraethoxypropane malonaldehyde (MDA) quantified through the TBARS method is one of the most abundant aldehydes generated during secondary lipid oxidation and is probably the most commonly used as an oxidation marker (Shahidi et al., 2015). From the results, it can be seen that the E extract of the leaf of $C$. longa $\mathrm{L}$. at $1.0 \%$ concentration tested at $60^{\circ} \mathrm{C}$ presented a similar response to the BHT from the $6^{\text {th }}$ day. The TBARS in the soy oil containing $1.5 \%$ of extract at $70^{\circ} \mathrm{C}$ was lower than in the soybean oil containing BHT in the evaluated period. The soybean oil containing $0.5 \%$ of extract had a similar response to the control until the $6^{\text {th }}$ day. Therefore, TBARS was lower than that shown in the positive control. These results were similar to those of the PI. This was expected since TBARS represents the secondary oxidation compounds which are derived from the degradation of the hydroperoxides represented by the PI (Shahidi et al., 2015). The greatest formation of secondary oxidation compounds happed on day 6 with a decrease on day 9 and a later increase until the end of the experiment. In general, the TBARS values showed an increasing trend during the food storage period with no standardization (Zhang et al., 2017). According to Matumoto-Pintro et al. (2017), aldehydes are secondary oxidation compounds that are produced by the decomposition of DC. These primary oxidation compounds are better identified in longer storage times. The storage temperature also influenced the lipid oxidation during the storage period.

Conjugated dienes and trienes (CD/CT). The results of CD and CT are shown in Table 3. The hydroperoxide formed from unsaturated fatty acids is usually accompanied by the stabilization of the radical state through the rearrangement of double bonds (electron displacement) which allows the formation of $\mathrm{CD}$ and TC during the propagation stage of oxidation (Wardhani et al., 2013). The results obtained showed the formation of $\mathrm{CD}$ and $\mathrm{CT}$ reduced from day 3 in oils containing $1.0 \%$ of extract at $60^{\circ} \mathrm{C}$. These oils presented lower values of $\mathrm{CD}$ and $\mathrm{CT}$ when compared to the control using BHT, especially on the $6^{\text {th }}$ day. This protection against oxidative degradation obtained by the addition of the leaf extract of $C$. longa $\mathrm{L}$. may be the result of the ability of natural phenolic compounds to slow the rate of formation of $\mathrm{CD}$ and to protect against the degradation of linoleic acid. Phenolics transfer hydrogen atoms to lipid peroxyl radicals in order to quench the radical process (Mohd Nor et al., 2009).

Baştürk et al. (2018) reported that CD had an almost linear increase (1.6 to 7.1) in 6 weeks of accelerated storage testing, whereas the $\mathrm{CT}$ values fluctuated during the evaluated period ( 0.233 to 2.18 ). This behavior was similar to what was observed in this present study. CD ranged from 1.16 to 8.62 and CT from 0.32 to 1.89 in the $1.0 \%$ extract at $60^{\circ} \mathrm{C}$. It was observed that the values varied more in the $1.0 \%$ and $1.5 \%$ extracts among the other concentrations. Higher concentrations of extracts had a bigger influence on the inhibition of the formation of these compounds. CDs can be used to measure the primary oxidation, which can be correlated with PI (Zamuz et al., 2018). The same can be verified for $1.0 \%$ extracts at $60^{\circ} \mathrm{C}$.

According to the data presented, the temperature of $50^{\circ} \mathrm{C}$ was the best condition, as it did not strongly induce the formation of primary and secondary compounds of PI oxidation under any of the experimental conditions. However, different concentrations of the extract had no significant effect on the response variables. The temperature was then the only limiting factor of the test. It was also observed that on the $6^{\text {th }}$ day of the oxidative stability tests the best response for the extracts was seen, which was demonstrated by the reduction in the results of PI, TBARS, CD and CT. The data showed that after this day all the parameters increased considerably. When considering that in 24 hours at $65^{\circ} \mathrm{C}$ it corresponds to a month of storage at room temperature (Sadeghi et al., 2017), the period of best response of the extracts corresponds to approximately 6 months of storage of soy oil at this temperature. It can be inferred that 6 months would be the maximum time that the antioxidant capacity of the extract $\mathrm{E}$ of the leaves of $C$. long $a \mathrm{~L}$. would be effective under the conditions tested.

Statistical analysis. The effects of the variables of temperature and extract concentration relating to time are shown in Table 4 for each variable response: PI, TBARS and CD/CT.

It can be seen in Table 4 that the effects of the independent variables, concentration and temperature were not statistically significant at the significance level of $5 \%(p<0.05)$ in the PI, TBARS, CD and CT responses. 
Alves, I. de Paula Duarte, Almeida de, M. C., Souto Reis Fontinelle, L., Ferreira de Oliveira, T. (2021). The effects of Curcuma longa L. leaf extracts on the prevention of oxidation in soybean oil. Acta Sci. Pol. Technol. Aliment., 20(3), 325-336. http://dx.doi.org/10.17306/ J.AFS.2021.0894

Table 3. Conjugated dienes (CD) and trienes (CT) in soybean oil subjected to accelerated storage test for 12 days

\begin{tabular}{|c|c|c|c|c|c|c|c|}
\hline \multirow{2}{*}{ Tests } & \multirow{2}{*}{$\begin{array}{c}x_{1} \\
\mathrm{C}, \%\end{array}$} & \multirow{2}{*}{$\begin{array}{c}x_{2} \\
\mathrm{~T},{ }^{\circ} \mathrm{C}\end{array}$} & \multicolumn{5}{|c|}{ Time, days } \\
\hline & & & 0 & 3 & 6 & 9 & 12 \\
\hline \multicolumn{8}{|c|}{ Conjugated dienes (CD) } \\
\hline \multirow[t]{3}{*}{ Blank } & - & 50 & $4.11 \pm 0.17$ & $4.42 \pm 0.2$ & $3.88 \pm 0.09$ & $4.33 \pm 0.03$ & $4.74 \pm 0.05$ \\
\hline & - & 60 & $4.11 \pm 0.17$ & $4.37 \pm 0.03$ & $8.03 \pm 0.00$ & $12.73 \pm 0.01$ & $17.35 \pm 0.75$ \\
\hline & - & 70 & $4.11 \pm 0.17$ & $5.52 \pm 0.01$ & $8.53 \pm 0.06$ & $16.13 \pm 0.04$ & $17.35 \pm 0.35$ \\
\hline \multirow[t]{3}{*}{ Control (BHT) } & - & 50 & $4.12 \pm 0.04$ & $4.35 \pm 0.08$ & $3.93 \pm 0.05$ & $4.27 \pm 0.03$ & $4.42 \pm 0.03$ \\
\hline & - & 60 & $4.12 \pm 0.04$ & $4.49 \pm 0.08$ & $5.18 \pm 0.03$ & $8.05 \pm 0.07$ & $12.43 \pm 0.02$ \\
\hline & - & 70 & $4.12 \pm 0.04$ & $6.42 \pm 0.00$ & $7.97 \pm 0.31$ & $12.73 \pm 0.11$ & $14.24 \pm 0.14$ \\
\hline $\mathrm{C} 1$ & 0.5 & 50 & $4.05 \pm 0.01$ & $4.20 \pm 0.04$ & $3.41 \pm 0.02$ & $4.47 \pm 0.10$ & $4.91 \pm 0.07$ \\
\hline $\mathrm{C} 2$ & 0.5 & 70 & $4.05 \pm 0.01$ & $5.46 \pm 0.01$ & $5.60 \pm 0.01$ & $12.43 \pm 0.02$ & $14.50 \pm 0.05$ \\
\hline $\mathrm{C} 3$ & 1.5 & 50 & $3.81 \pm 0.03$ & $1.78 \pm 0.00$ & $4.12 \pm 0.04$ & $4.49 \pm 0.00$ & $4.34 \pm 0.26$ \\
\hline $\mathrm{C} 4$ & 1.5 & 70 & $3.81 \pm 0.01$ & $1.97 \pm 0.03$ & $5.32 \pm 0.02$ & $11.49 \pm 0.02$ & $12.98 \pm 0.03$ \\
\hline C5 & 1.0 & 60 & $3.04 \pm 0.03$ & $3.96 \pm 0.00$ & $1.79 \pm 0.00$ & $1.57 \pm 0.00$ & $13.84 \pm 0.67$ \\
\hline C6 & 1.0 & 60 & $3.04 \pm 0.03$ & $2.06 \pm 0.01$ & $0.45 \pm 0.02$ & $0.60 \pm 0.02$ & $0.83 \pm 0.02$ \\
\hline $\mathrm{C} 7$ & 1.0 & 60 & $3.04 \pm 0.03$ & $4.22 \pm 0.05$ & $1.23 \pm 0.04$ & $8.69 \pm 0.01$ & $11.19 \pm 0.10$ \\
\hline \multicolumn{8}{|c|}{ Conjugated trienes (CT) } \\
\hline \multirow[t]{3}{*}{ Blank } & - & 50 & $3.47 \pm 0.01$ & $1.93 \pm 0.14$ & $1.70 \pm 0.06$ & $1.84 \pm 0.01$ & $1.81 \pm 0.02$ \\
\hline & - & 60 & $3.47 \pm 0.01$ & $1.73 \pm 0.01$ & $1.83 \pm 0.00$ & $2.39 \pm 0.00$ & $1.95 \pm 0.00$ \\
\hline & - & 70 & $3.47 \pm 0.01$ & $1.82 \pm 0.00$ & $1.75 \pm 0.00$ & $2.09 \pm 0.00$ & $1.95 \pm 0.03$ \\
\hline \multirow[t]{3}{*}{ Control (BHT) } & - & 50 & $1.71 \pm 0.01$ & $1.79 \pm 0.02$ & $1.71 \pm 0.02$ & $1.82 \pm 0.02$ & $1.79 \pm 0.04$ \\
\hline & - & 60 & $1.71 \pm 0.01$ & $1.84 \pm 0.05$ & $1.74 \pm 0.00$ & $2.56 \pm 0.04$ & $1.93 \pm 0.00$ \\
\hline & - & 70 & $1.71 \pm 0.01$ & $1.98 \pm 0.01$ & $1.79 \pm 0.00$ & $2.03 \pm 0.01$ & $2.16 \pm 0.01$ \\
\hline $\mathrm{C} 1$ & 0.5 & 50 & $1.84 \pm 0.02$ & $1.78 \pm 0.02$ & $1.23 \pm 0.00$ & $1.85 \pm 0.01$ & $1.81 \pm 0.02$ \\
\hline $\mathrm{C} 2$ & 0.5 & 70 & $1.84 \pm 0.02$ & $1.99 \pm 0.01$ & $1.81 \pm 0.01$ & $1.97 \pm 0.01$ & $2.14 \pm 0.01$ \\
\hline $\mathrm{C} 3$ & 1.5 & 50 & $1.90 \pm 0.01$ & $1.69 \pm 0.05$ & $1.73 \pm 0.00$ & $1.86 \pm 0.01$ & $1.79 \pm 0.02$ \\
\hline $\mathrm{C} 4$ & 1.5 & 70 & $1.90 \pm 0.01$ & $0.65 \pm 0.01$ & $1.48 \pm 0.02$ & $1.97 \pm 0.00$ & $1.94 \pm 0.02$ \\
\hline C5 & 1.0 & 60 & $1.34 \pm 0.03$ & $1.58 \pm 0.00$ & $0.21 \pm 0.00$ & $0.32 \pm 0.01$ & $2.01 \pm 0.00$ \\
\hline C6 & 1.0 & 60 & $1.34 \pm 0.03$ & $1.58 \pm 0.00$ & $0.33 \pm 0.00$ & $0.25 \pm 0.03$ & $1.88 \pm 0.00$ \\
\hline $\mathrm{C} 7$ & 1.0 & 60 & $1.34 \pm 0.03$ & $1.83 \pm 0.01$ & $0.41 \pm 0.02$ & $1.83 \pm 0.02$ & $1.77 \pm 0.00$ \\
\hline
\end{tabular}

Values constitute mean \pm standard deviation of two repetitions.

$\mathrm{C}$ - concentration, $\mathrm{T}$ - temperature. 
Alves, I. de Paula Duarte, Almeida de, M. C., Souto Reis Fontinelle, L., Ferreira de Oliveira, T. (2021). The effects of Curcuma longa L. leaf extracts on the prevention of oxidation in soybean oil. Acta Sci. Pol. Technol. Aliment., 20(3), 325-336. http://dx.doi.org/10.17306/ J.AFS.2021.0894

Table 4. Estimation of the effects of variables as a function of time

\begin{tabular}{lccccccccc}
\hline \multirow{2}{*}{ Variable } & \multicolumn{2}{c}{ PI } & \multicolumn{2}{c}{ TBARS } & \multicolumn{2}{c}{ CD } & \multicolumn{2}{c}{ CT } \\
\cline { 2 - 26 } & effect & $p$ & effect & $p$ & effect & $p$ & effect & $p$ \\
\hline Concentration, $\%$ & 0.499 & 0.682 & -0.039 & 0.443 & -0.244 & 0.741 & 0.066 & 0.878 \\
Temperature, ${ }^{\circ} \mathrm{C}$ & 0.000 & 0.999 & 0.000 & 1.000 & 0.000 & 0.999 & 0.000 & 1.000 \\
\hline
\end{tabular}

Significance level $p>0.05$.

PI - peroxide index, TBARS - thiobarbituric acid reactive substances, CD - conjugated dienes, CT - conjugated trienes.

The concentration had a positive effect on the PI and $\mathrm{CT}$ values and a negative effect on the TBARS and CD values. This demonstrates that the variation in the concentration of the leaf extract of $C$. longa L. presents a better response over the secondary oxidation compounds represented by TBARS.

Regarding the effects of extract concentration, Wardhani et al. (2013) observed that with larger amounts of the antioxidant of soy extract fermented in lipid emulsions and sunflower oil, there was a negative effect on the inhibition of primary oxidation causing a decrease in lipid oxidation. According to these authors, the presence of the extract suppressed oxidation in a concentration-dependent manner. As for the temperature, it was observed that it positively affected the four parameters evaluated. It is known that higher temperatures for a certain time can increase the pro-oxidant capacity in food, likely due to the loss of natural antioxidants and the formation of oxidative molecules (Matumoto-Pintro et al., 2017). The results of the oxidative stability tests of vegetable oils submitted to thermal treatments are highly variable. The polyphenol profile of plant species, the extraction methods, the concentrated extract and the low content of lipophilic phenolic compounds in antioxidants are factors that impact the antioxidant capacity. Regarding the nature of the oil, the main factors are the degree of unsaturation, the temperature and the method used for the oxidation of lipids (polar compounds, PI, DC and TC), among others (Jiménez et al., 2017).

\section{CONCLUSIONS}

The EW extract showed the highest yield in extracting the phenolic compound as a safe solvent for food. The addition of Curcuma longa L. leaf extract to soybean oil caused reductions in PI, TBARS, CD and CT values. This extraction showed equivalent or more efficient results when compared to BHT, contributing to the oxidative stability of the product. Thus, the leaves of $C$. longa $\mathrm{L}$. can be used as a potential source of natural antioxidants to be exploited by the food industry in vegetable oils. Future studies will be able to identify the compounds responsible for the antioxidant capacity of these leaves and evaluate the synergistic effect of these natural antioxidants with other natural or synthetic ones.

\section{REFERENCES}

AOCS (1990). Official methods and recommended practices of American Oil Chemists' Society. A.C.S. Official method Ch 5-91. Champaign, USA: American Oil Chemists' Society.

AOCS (2003). Official methods and recommended practices of the AOCS Cd 8b-90 (4th ed.). Champaign: American Oil Chemists' Society.

Alizadeh, L., Abdolmaleki, K., Nayebzadeh. K., Shahin, R. (2019). Effects of tocopherol. Rosemary essential oil and Ferulago angulata extract on oxidative stability of mayonnaise during its shelf life: A comparative study. Food Chem., 285, 46-52.

Balboa, E. M., Soto, M. L., Nogueira, D. R., González-López, N., Conde, E., Moure, A., Domínguez, H. (2014). Potential of antioxidant extracts produced by aqueous processing of renewable resources for the formulation of cosmetics. Ind. Crops Prod., 58, 104-110.

Baştürk, A., Ceylan, M. M., Çavuş, M., Boran, G., Javidipour, I. (2018). Effects of some herbal extracts on oxidative stability of corn oil under accelerated oxidation conditions in comparison with some commonly used antioxidants. LWT - Food Sci. Technol., 89, 358-364. 
Alves, I. de Paula Duarte, Almeida de, M. C., Souto Reis Fontinelle, L., Ferreira de Oliveira, T. (2021). The effects of Curcuma longa L. leaf extracts on the prevention of oxidation in soybean oil. Acta Sci. Pol. Technol. Aliment., 20(3), 325-336. http://dx.doi.org/10.17306/ J.AFS.2021.0894

Braga, M. C., Vieira, E. C. S., Oliveira, T. F. (2018). C. longa L. leaves: Characterization (bioactive and antinutritional compounds) for use in human food in Brazil. Food Chem., 265, 308-315.

Carocho, M., Morales, P., Ferreira, I. C. F. R. (2018). Antioxidants: Reviewing the chemistry. Food applications. legislation and role as preservatives. Trends Food Sci. Technol., 71, 107-120.

Chan, E. W. C., Lim, Y. Y., Lim, T. Y. (2007). Total phenolic content and antioxidant activity of leaves and rhizomes of some ginger species in Peninsular Malaysia. Gardens' Bull. Singapore, 59(1-2), 47-56.

FAO - Food and Agriculture Organization of the United Nations (1999). Codex standard for edible fats and oils not covered by individual standards (CODEX STAN 19-1981. Rev. 2 - 1999).

Jiménez, P., García, P., Bustamante, A., Barriga, A., Robert, P. (2017). Thermal stability of oils added with avocado (Persea americana cv. Hass) or olive (Olea europaea cv. Arbequina) leaf extracts during the French potatoes frying. Food Chem., 221, 123-129.

Matumoto-Pintro, P. T., Murakami, A. E., Vital, A. C. P., Croge, C., da Silva, D. F., Ospina-Roja, I. C., Guerra, A. F. Q. G. (2017). Effects of storage time and temperature on lipid oxidation of egg powders enriched with natural antioxidants. Food Chem., 228, 463-468.

Michiels, J. A., Kevers, C., Pincemail, J., Defraigne, J. O., Dommes, J. (2012). Extraction conditions can greatly influence antioxidant capacity assays in plant food matrices. Food Chem., 130(4), 986-993.

Mohd Nor, F., Mohamed, S., Idris, N. A., Ismail, R. (2009). Antioxidative properties of Curcuma longa leaf extract in accelerated oxidation and deep frying studies. J. Am. Oil Chem. Soc., 86(2), 141-147.

Noon, J., Mills, T. B., Norton, I. T. (2020). The use of natural antioxidants to combat lipid oxidation in $\mathrm{O} / \mathrm{W}$ emulsions. J. Food Eng., 281, 110006.

Pedro, A. C., Maurer, J. B. B., Zawadzki-Baggio, S. F., Ávila, S., Maciel, G. M., Haminiuk, C. W. I. (2018). Bioactive compounds of organic goji berry (Lycium barbarum L.) prevents oxidative deterioration of soybean oil. Ind. Crops Prod., 112, 90-97.

Pérez-Jiménez, J., Saura-Calixto, F. (2006). Effect of solvent and certain food constituents on different antioxidant capacity assays. Food Res. Inter., 39(7), 791-800.

Priya, R., Prathapan, A., Raghu, K. G., Menon, A. N. (2012). Chemical composition and in vitro antioxidative potential of oil isolated from Curcuma longa L. leaves. Asia-Pac. J. Trop. Biomed., 2(2), 695-699.
Sadeghi, E., Karami, F., Etminan, A. (2017). The effect of Ferulago angulata (Schlecht) boiss essential oil on stabilization of sunflower oil during accelerated storage. J. Food Proc. Preserv., 41(1). https://doi.org/10.1111/ jfpp. 12745

Pulido, R., Bravo, L., Saura-Calixto, F. (2000). Antioxidant activity of dietary polyphenols as determined by a modified ferric reducing/antioxidant power assay. J. Agric. Food Chem., 48(8), 3396-3402.

Shahidi, F., Ambigaipalan, P. (2015). Phenolics and polyphenolics in foods, everages and spices: Antioxidant activity and health effects - A review. J. Funct. Foods, $18,820-897$.

Taghvaei, M., Jafari, S. M. (2015). Application and stability of natural antioxidants in edible oils in order to substitute synthetic additives. J. Food Sci. Techn., 52, 1272-1282. https://doi.org/10.1007/s13197-013-1080-1

Tarladgis, B. G., Watts, B. M., Younathan, M. T., Dugan, L. (1960). A distillation method for the quantitative determination of malonaldehyde in rancid foods. J. Am. Oil Chem. Soc., 37(1), 44-48.

Wang, L., Luo, Y., Wu, Y., Xia, F., Wu, Z. (2018). Quickly verifying the antioxidant contribution of the individual composition in natural antioxidants by HPLC-free radical scavenging. LWT, 96, 461-468. https://doi. org/10.1016/j.lwt.2018.06.005

Wardhani, D. H., Fuciños, P., Vázquez, J. A., Pandiella, S. S. (2013). Inhibition kinetics of lipid oxidation of foods by using antioxidant extract of fermented soybeans. Food Chem., 139(1-4), 837-844.

Wojcik, M., Krawczyk, M., Wojcik, P., Cypryk, K., Wozniak, L. A. (2018). Molecular mechanisms underlying curcumin-mediated therap. Effects in type 2 diabetes and cancer. Oxid. Med. Cell. Longev., ID 9698258. https://doi.org/10.1155/2018/9698258

Yeşilsu, A. F., Özyurt, G. (2019). Oxidative stability of microencapsulated fish oil with rosemary. thyme and laurel extracts: A kinetic assessment. J. Food Engin., 240(14), 171-182.

Zamuz, S., López-Pedrouso, M., Barba, F. J., Lorenzo, J. M., Domínguez, H., Franco, D. (2018). Application of hull, bur and leaf chestnut extracts on the shelf-life of beef patties stored under MAP: Evaluation of their impact on physicochemical properties, lipid oxidation, antioxidant, and antimicrobial potential. Food Res. Inter., 112, 263-273.

Zhang, L., Yang, Z., Chen, F., Su, P., Chen, D., Pan, W., $\mathrm{Du}, \mathrm{Z}$. (2017). Composition and bioactivity assessment of essential oils of C. longa L. collected in China. Ind. Crops Prod., 109, 60-73. 
Alves, I. de Paula Duarte, Almeida de, M. C., Souto Reis Fontinelle, L., Ferreira de Oliveira, T. (2021). The effects of Curcuma longa L. leaf extracts on the prevention of oxidation in soybean oil. Acta Sci. Pol. Technol. Aliment., 20(3), 325-336. http://dx.doi.org/10.17306/ J.AFS.2021.0894

Złotek, U., Mikulska, S., Nagajek, M., Świeca, M. (2016). The effect of different solvents and number of extraction steps on the polyphenol content and antioxidant capacity of basil leaves (Ocimum basilicum L.) extracts. Saudi J. Biol. Sci., 23(5), 628-633.
Pulido, R., Bravo, L., Saura-Calixto, F. (2000). Antioxidant activity of dietary polyphenols as determined by a modified ferric reducing/antioxidant power assay. J. Agric. Food Chem., 48, 8, 3396-3402. https://doi.org/10.1021/ jf9913458 